\title{
"The realities of their world": Engaging Pre-service School Librarians with International Literature
}

\author{
Dr. Kasey L. Garrison \\ Charles Sturt University \\ Faculty of Education, School of Information Studies \\ Locked Bag 588 \\ Wagga Wagga, NSW 2678 \\ Australia \\ kgarrison@csu.edu.au \\ Dr. Danielle E. Forest \\ University of Southern Mississippi \\ Department of Curriculum, Instruction \& Special Education \\ 118 College Drive, \#5057 \\ J.B. George Building, \#143 \\ Hattiesburg, MS 39406 \\ United States of America \\ danielle.forest@usm.edu \\ Dr. Sue Kimmel \\ Old Dominion University \\ Darden College of Education, Department of Teaching and Learning \\ Education Building \\ Norfolk, VA 23529 \\ United States of America \\ skimmel@odu.edu
}

\begin{abstract}
As the idea of global citizenship grows stronger in a world with blurring borders, issues of social justice and international human rights should be available in the school library collection and alive in the curriculum. This paper reports findings on a study exploring the perceptions of preservice educators in using international literature to teach youth about international human rights. The 2013 Batchelder Honor title Son of a Gun (de Graaf, 2012), translated from the Dutch into English, tells the story of a young brother and sister forced to become child soldiers during the Liberian civil war of the 1990s. Study participants enrolled in a masters level course in the United States read the title and the United Nations' Declaration of the Rights of the Child (1959) and then participated in group literature circles to apply the DRC to Son of a Gun and discuss teaching international human rights to youth.
\end{abstract}

Keywords: international human rights, global literature, translated literature, literature circles, global citizenship 


\section{Introduction}

As people across the world become more interconnected than ever before, the need for global awareness becomes increasingly imperative. The school library is in a strategic position in the school community to be the place where students can experience other cultures and learn more about their world, both past and present. The school library may also be a place where students are encouraged to develop awareness of international human rights issues. Unfortunately, human rights education is rarely taught in schools in the United States today (Dunkerly-Bean, 2013). However, including international and global literature in the school library collection is a practical way to offer opportunities for students to explore issues such as social justice and international human rights.

In this study, our purpose was to investigate the perceptions pre-service teachers and school librarians had about using an international children's book to promote awareness, discussion, and activism related to international human rights with their students. We used Anne de Graaf's (2012) novel Son of a Gun, a book about child soldiers in war-torn 1990s Liberia, to facilitate literature circle discussions about human rights in the context of an online children's literature class. Discussions were framed within the United Nations' 1959 Declaration of the Rights of the Child (DRC), a document outlining ten fundamental rights such as an education, medical care, a name, and even love that every child in the world deserves "without any exception whatsoever" (UN, 1959). The study was guided by the following questions:

1. What meanings do participants make after reading Son of a Gun (de Graaf, 2012)?

a. What are their overall perceptions of the quality and appeal of the book?

b. What are their perceptions of using the book with children?

c. What connections do they draw between this title and the $D R C$ ?

d. What are their perceptions of using the book to understand and teach about international human rights with youth?

\section{Literature Review}

The literature review which follows addresses the use of literature circles to discuss social justice issues, the potential of international literature to facilitate global awareness and understanding, and some background about de Graaf's (2012) novel and the DRC (UN, 1959).

\section{Literature Circles}

Other studies have used literature circles with pre-service teachers as a way to understand their pedagogical perspectives on learning, encourage the integration of literature into their practice, and study the impact of participants' cultural backgrounds and experiences on their teaching (Alger, 2007; Escamilla \& Nathenson-Mejía, 2003; Thein, Guise, \& Sloan, 2012). In an effort to promote cultural responsiveness in a class of predominantly White pre-service teachers, Escamilla and Nathenson-Mejía (2003) used Latino children's literature in literature circles. Through the discussions, the students made universal connections with characters and situations in the stories, but were also hesitant to address more controversial content in the titles based on cultural differences. An example was the presumed focus on death in the Latin American holiday, El Día de Los Muertos, where families celebrate and remember their 
deceased friends and family. Thein et al. (2012) found that using children's literature dealing with social class issues and then discussing these titles via literature circles encouraged preservice and in-service teacher participants to inquire about social class issues at the local level that may be directly impacting their students. Alger (2007) found success in using professional titles in literature circles with pre-service teachers to force them to confront their perspectives on illiteracy with older students. The findings from these studies give our research a base for using literature circles to investigate how pre-service teacher librarians can use international children's literature to engage students in discussions of social justice and human rights and develop global citizenship.

\section{International Literature}

Scholars have called on educators from primary to secondary levels to engage youth in discussions and action on topics such as social justice and international human rights (Grant \& Gibson, 2013; Martin, Smolen, Oswald, \& Milam, 2012). Including international literature in the school library is one way that educators might foster such global awareness. International literature refers to books that were originally published outside the United States; it is distinct from global literature, which refers to books that are set outside of the United States but may have been written by American authors (Montero \& Robertson, 2006; Moreillon, 2013). Reading books with international origins is regarded as a means of promoting appreciation of other cultures as well as developing respect for diversity (Buck et al., 2011; Louie \& Louie, 1999). International literature "has a key role to play in developing our young people's global understandings" (Moreillon, 2013, p. 35).

Unfortunately, international children's literature is risky business for American publishers. International books do not sell well and can be more expensive to produce than books with domestic origins (Biamonte, 2002). However, in order to encourage the publication of international children's literature in the United States, the Association for Library Service to Children (ALSC), a division of the American Library Association, established the Mildred L. Batchelder Award in 1966. The Batchelder Award's intent is "to encourage American publishers to seek out superior children's books abroad and to promote communication among the peoples of the world" (ALSC, 2014, para. 2). The award is given annually to an outstanding children's title originally published outside of the United States, translated to English, and then published for an American audience. Though one award winner is selected, the ALSC committee has the option of conferring the Batchelder Honor on quality titles that also merit literary recognition. Batchelder books thus make selection of high quality international literature simplified for librarians and teachers. Access to these books also opens the possibility for engaging youth with international literature in order to show them other ways of life and encourage them to consider global issues.

\section{Son of a Gun (de Graaf, 2012)}

Son of a Gun (de Graaf, 2012), originally published in Dutch in the Netherlands, is set during Liberian civil war in the early 1990s when children were kidnapped from villages and forced to fight as soldiers in the conflict. While the story is fiction, de Graaf did extensive research including interviews with former child soldiers to tell the story of brother Lucky and sister Nopi. 
This book was selected for our study because it is a current example of international literature that addresses an ongoing global issue: child soldiers (see Mangier, 2013). Additionally, Son of a Gun (de Graaf, 2012) has been recognized for its literary merit: ALSC awarded it with a 2013 Batchelder Honor. Further, Anne de Graaf both wrote the original Dutch version of the book and translated it to English, which curtails some of the issues involved with what can get lost in a translation like names and cultural context (see Metcalf, 2003; Yamazaki, 2002). Moreover, Son of a Gun (de Graaf, 2012) is a strong reflection of what can happen to children when a society fails to support the beliefs expounded in the DRC (UN, 1959). Thus, it was an appropriate choice for our goal of addressing international human rights using children's literature within online literature circle discussion.

\section{The Declaration of the Rights of the Child (UN, 1959)}

The DRC (UN, 1959) was chosen as a framework to examine the violations of the basic rights of Nopi, Lucky, and the other child soldiers in the novel, Son of a Gun (UN, 1959). The researchers have previously used the DRC (UN, 1959) to do content analyses and examinations of the content within international children's titles that have won the Batchelder Award or Honor since 2000 (see Garrison, Kimmel, \& Forest, 2013; Garrison, Kimmel, \& Forest, 2014). This document holds strong potential for engaging children in discussions and activism efforts regarding international human rights and other social justice issues around the world. The United Nations includes a plain language version of the rights which would be useful to use with children in lieu of the more formal, official version. (See Appendix A. for the Plain Language version.) This is the format we used in this study and shared with our participants.

\section{Methods}

This study employed a qualitative design to investigate the research questions listed above. The participants in this study were pre-service school librarians and teachers enrolled in two sections of an online children's literature class as part of their Masters of Education coursework from August to December 2013 at a university in the United States. In this class, groups of four to five students participate in synchronous, digital literature circles to gain experience with this teaching strategy while interacting with children's books. As part of this assignment, students were required to: 1) read Son of a Gun independently; 2) read the $D R C$; 3) choose and prepare roles for the literature circles (e.g. leader, summarizer); 4) create questions to accompany the discussion, relating them to the $D R C ; 5)$ record the transcript of the talk on their course website; and 6) submit a reflection of the discussion following the experience. The students' work including the questions, reflection, and recorded transcripts became the data sources analyzed to investigate the research questions. Sixteen students participated in this study and a research assistant pulled their responses and discussions from the literature circle transcripts and gathered their work from the class instructors. A qualitative data analysis approach was employed to code and analyze each of these data sources (Merriam, 2009). Each researcher was assigned a research sub-question and read through the data sources to find references to these topics. The research team then gathered to review the data as a team and discuss the findings holistically as well as for each sub-question. 


\section{Findings}

Our overarching research question sought to explore the meanings pre-service teachers and school librarians made after reading the 2013 Batchelder Honor title Son of a Gun (de Graaf, 2012) and the DRC (UN, 1959). Findings revealed interesting and divergent perspectives from the participants. These are organized by each of the four sub-questions.

\section{Appeal and Quality of the Book}

Based on the transcripts of the literature circle discussions, it is evident that this book was appealing to the participants themselves. While some felt the book and violent topic of child soldiers and war would be difficult for youth, others noted it as an important read for all. The title for this paper given by Claudia ("Sometimes we have to expose children to 'the realities of their world"') expounds this view as well as that of Alice who "made [her] nieces and nephews read it." Several participants were very engaged with the book, noting they "couldn't put it down" and that it was inspirational, "a great story of not giving up." They especially appreciated how the author's real-life interactions with former child soldiers informed the story. A few mentioned being particularly interested in the author's notes at the end of the story, where the author describes her experiences with children who have experienced war. These notes seemed to add quality to the book as participants described it as more "authentic" and "genuine" to them.

At the same time, participants also noted that the book was difficult to read due to the content. One participant called the book "heart-wrenching." In addition to the harsh nature of the content noted as an unsatisfactory quality of the book, one participant remarked that the characterization of Nopi poor and under-developed. Nonetheless, a few thought it would be too difficult (in terms of content) for children while others felt children would still enjoy the book.

\section{Using the Book with Children}

While students saw promise in using this book with youth to engage in discussions about international human rights, the age appropriateness of the novel was a subject of disagreement. The language and reading level of the book are low and students agreed that middle school aged youth could read it independently and comprehend it. However, the topics of violence in the content made them think it would be more emotionally appropriate for secondary students. There was a discussion in one of the groups about the need for parental consent to read the book. It was also suggested by Rosa to use the book "as a reading choice for a student who want to read it," but not a required read. It is important to note here that many of the allusions to violence are implicitly described and not explicit in nature. de Graaf (2012) gives tactful descriptions without graphic details so the reader must often infer what is occurring as in the discussion of rape that Nopi has with another young girl (both made "wives" to the same soldier) who has become pregnant.

Nonetheless, participants noted specific groups of readers that would benefit from engaging with Son of a Gun (de Graaf, 2010). Lisa said, "I think this would be a great book for students with disabilities to read to see [Nopi's] courage and resilience" as the main character becomes deaf during a battle. In the questions the students made pre-circle, Alexis directly addressed social issues enlisting the readers to consider what "educationally privileged students in 
America" would think about the nature of school in Liberia at the time of this novel. This question may have further implications given the recent events in Nigeria where 276 girls were kidnapped from their school by militants on April 14, 2014 (Abubakar, 2014).

Participants also discussed curriculum connections and uses for the title in the classroom. Some noted its practicality in a writing assignment. Alexis had an array of ideas to use this book with youth and support global citizenship and awareness. In particular, Alexis described how it could be used to help discuss "the impact that slavery in America had on other countries." She talked about the book being a "great way to tie in classroom cultures" through a pen pal program. She also suggested using Skype as a way "to really break down barriers that prevent students from having a global understanding of the world." Alexis was also a participant who brought up the idea of sister cities and making connections with other countries through that avenue.

\section{Connections with the DRC (UN, 1959)}

The DRC (UN, 1959) was used as a framework for students to consider how the rights of Nopi and Lucky were condemned during the novel. Students mentioned the $D R C$ in the questions they created prior to the literature circle discussions. Examples of these questions are listed in Table 1. 
Table 1. Literature Circle Questions from Participants

\begin{tabular}{|l|l|}
\hline Student Pseudonym & \multicolumn{1}{|c|}{ Question } \\
\hline Kristy & $\begin{array}{c}\text { In the second point it says that children will be protected "to enable } \\
\text { him to develop physically, mentally, morally, spiritually, and } \\
\text { socially in a healthy and normal manner and in conditions of } \\
\text { freedom and dignity." How did Lucky and Nopi develop in these } \\
\text { areas, was it normal, if not, what was affected? }\end{array}$ \\
\hline Lucy & $\begin{array}{l}\text { What, if any, steps should be taken by the United Nations to ensure } \\
\text { children are protected during civil wars? }\end{array}$ \\
\hline Melanie & $\begin{array}{l}\text { There are still children soldiers in more than 25 countries today. How } \\
\text { is it that with stories like Nopi and Lucky and the laws of the } \\
\text { Declaration of the Rights of the Child that countries are still } \\
\text { employing children into war? }\end{array}$ \\
\hline Courtney & $\begin{array}{l}\text { How could Nopi's and Lucky's involvement in the war be different if } \\
\text { the Declaration of the Rights of a Child were intact? }\end{array}$ \\
\hline Katie & $\begin{array}{l}\text { What are some examples of direct violation of the Declaration of the } \\
\text { Rights of the Child in Son of a Gun? }\end{array}$ \\
\hline Angela & $\begin{array}{l}\text { Number } 5 \text { says you have a right to special care if you are } \\
\text { handicapped. Why does Nopi not want anyone to know she is } \\
\text { deaf? }\end{array}$ \\
\hline
\end{tabular}

During the literature circles, a common theme of accountability occupied the discussions in regards to the $D R C$ (1959). Participants asked each other who was responsible, how they could be brought to justice, and how such terrible events can be rectified. Katie compared the plight of child soldiers with that of the Jews in the Holocaust during World War II. Lisa summarized her group's discussion in such terms:

"We held a long discussion on who we thought was responsible or should be held accountable for the abuse of these child soldiers. We all agreed that according the Declaration of the Rights of Children, these children were not protected. We discussed that every adult that had a hand in the Liberian war and forcing these kids into adult roles should have been held accountable and also how impossible it was to track them all down. "

The students were able to use the $D R C(U N, 1959)$ as a framework for examining the different violations of international human rights in the title. It is clear from their discussion transcripts, pre-created circle questions, and discussion summaries that this was an effective tool for them personally to use. The next sub-question asked them to connect this to the classroom 


\section{Teaching Children about International Human Rights}

Participants had divergent perspectives on using this book to teach children about international human rights. In the title of this paper, Claudia noted that this global perspective offers the opportunity of "expos[ing] children to the realities of their world." Alexis also described the potential for Son of a Gun (de Graaf, 2012) to serve as a catalyst for discussions about the history of Liberia and other African countries and how current social issues in this area have been impacted on slavery of the past. At the same time, participants in the literature circles were mindful of the implications that discussions of violence and war could have in the classroom. Laurie and Meghan from the Green Group deliberate below:

Laurie: I think this book would pique the interests of children too to learn more about the war...

Megan: orscare [sic.] them.

Laurie: I think (de Graaf) did a good job of revealing just enough for kids to know what these children went through without making it to [sic.] gruesome and detailed.

Alexis from the Blue Group led an interesting discussion when she noted resources on the UN website for helping to teach youth about child soldiers. She made a connection to Son of a Gun (de Graaf, 2012) with Jerry Piasecki's book Marie, The Shadow of a Lion: A Humanitarian Novel (2000), which was published by the United Nations and includes a Teacher's Resource Guide on the Cyberschoolbus website for using with youth. Alexis noted that, "it is free to read and it is a similar perspective [to Son of a Gun], but from the view of a young girl who watches how the boys become killers." It is evident from the discussions among the participants that there are diverse perspectives on how to go about teaching youth about international human rights and perhaps if at all.

\section{Study Limitations}

There were some limitations to this study that need to be addressed. Firstly, while there were potentially 39 participants, only 16 students gave their consent. Since the students were not required to do anything extra beyond their class requirements, this was quite surprising. It is unclear why students did not agree to participant, but could perhaps been due to the extensive study description given to them in their participation request letter. This was created in order to fully address the requirements of the Human Subjects Review Board at the university, but it is possible the researchers could have simplified this slightly to be more welcoming to potential participants and still have passed the review.

Another interesting limitation that is not so obvious was the students' engagement with Son of a Gun (de Graaf, 2012). They got so into reading the book and the real-world pieces of the story that their discussions of using the book and the DRC (UN, 1959) with children were a bit muted. While this does reinforce that fact that the book is of literary quality and holds appeal for reading, more direct discussion about classroom applications would have enhanced the findings for this study. 


\section{Significance}

The search for culture is one that can and should begin in the world of the school library. As educators, we have a responsibility to give our students the opportunities to experience their world. International literature, like Son of a Gun (de Graaf, 2012), is a great way to offer these chances and encourage them to consider issues of social (in)justices in their own communities as well as the broader global context as noted in the DRC (UN, 1959). While discussions about the violations of international human rights and violence are no doubt difficult to have with children, having them in the school library gives students a safe place to unpack what these global issues mean for humanity and how they can make potential impacts. As shown in the literature review with the study of primary students, students are never too young to begin considering how they can enact change with social injustices in the world. Being informed and educated is the first step toward such changes and attitudes. There are useful resources out there to help guide teacher with these difficult topics. For example, the United Nations' Cyberschoolbus website which discusses global issues for children presents extensive information and a webquest about child soldiers around the world (For more information, see http://cyberschoolbus.un.org/childsoldiers/webquest/). This is a great start and reference for school librarians and educators hesitant to engage students in discussions of international human rights. As shown in this study, international children's literature holds strong potential in being another useful tool. 


\section{References}

Abubakar, (2014, June 2). Protests for kidnapped girls banned in Nigerian capital [Newsgroup post]. Retrieved from http://edition.cnn.com/2014/06/02/world/africa/nigeria-protestsban/?hpt=hp t1.

Alger, C.L. (2007). Engaging student teachers' hearts and minds in the struggle to address (il)literacy in content area classrooms. Journal of Adolescent \& Adult Literacy, 50(8), 620630 .

Association for Library Service to Children. (2014). About the (Mildred L.) Batchelder Award. Retrieved from http://www.ala.org/alsc/awardsgrants/bookmedia/ batchelderaward/batchelderabout

Biamonte, C. (2002). Crossing culture in children's book publishing. Publishing Research Quarterly, 18(3), 26-42.

Buck, C.C., Gilrane, C.P., Brown, C. L., Hendricks, D.A., Rearden, K.T., \& Wilson, N. (2011). There's hope in the story: Learning culture through international children's and young adult literature. The New England Reading Association Journal, 47(1), 49-59.

de Graaf, A. (2012). Son of a gun (A. de Graaf, Trans.). Grand Rapids, MI: Eerdmans Books for Young Readers.

Escamilla, K., \& Nathenson-Mejía, S. (2003). Preparing culturally responsive teachers: Using Latino children's literature in teacher education. Equity \& Excellence in Education, 36(3), 238-248.

Garrison, K. L., Kimmel, S.C., \& Forest, D. E. (2013). Reading across the world: Developing global citizenship through translated literature. Proceedings from the 42nd International Association of School Librarians' Annual Conference and the International Forum on Research in School Librarianship, Sanur, Bali, Indonesia.

Garrison, K.L., Kimmel, S.C, \& Forest, D.E. (2014). Curation in translation: Promoting global citizenship through literature. School Libraries Worldwide, 20(1), 70-96. Retrieved from http://iasl-online.mlanet.org/Resources/Documents/slw/v20/slw_v20n1_5garrison-final70-96.pdf.

Grant, C.A., \& Gibson, M.L. (2013). "The path of social justice: A human rights education history of social justice education. Equity and Excellence in Education, 46(1), 81-99.

Louie, B.Y., \& Louie, D.H. (1999). Global education through translated books. Journal of Children's Literature, 25(1), 34-43.

Mangier, M. (2013, August 7). Myanmar army releases child soldiers. Los Angeles Times. Retrieved from http://www.latimes.com/news/world/worldnow/la-fg-wn-myanmar-armyreleases-child-soldiers-20130807,0,7398316.story.

Martin, L.A., Smolen, L.A., Oswald, R.A., \& Milam, J.L. (2012). Preparing students for global citizenship in the twenty-first century: Integrating social justice through global literature. The Social Studies, 103, 158-164. doi: 10.1080/00377996.2011.601358

Metcalf, E. (2003). Exploring cultural difference through translating children's literature." Meta, $48(1 / 2), 322-27$ 
Montero, M.K., \& Robertson, J.M. (2006). "Teachers can't teach what they don't know": Teaching teachers about international and global children's literature to facilitate culturally responsive pedagogy. Journal of Children's Literature, 32(2), 27-35.

Moreillon, J. (2013). Building bridges for global understanding: Cultural literature collection development and programming. Children and Libraries: The Journal of the Association for Library Service to Children, 11(2), 35-38.

Piasecki, J. (2000). Marie, the shadow of a lion: A humanitarian novel. New York: United Nations.

Thein, A.H., Guise, M., \& Sloan, D.L. (2012). Exploring the significance of social class identity performance in the English classroom: A case study analysis of a literature circle discussion. English Education, 44(3), 215-253.

United Nations Cyberschoolbus. (n.d.) Child soldiers webquest. Retrieved from http://cyberschoolbus.un.org/childsoldiers/webquest/index.asp

United Nations General Assembly. (1959). Declaration of the Rights of the Child. Retrieved from: http://www.un.org/cyberschoolbus/humanrights/resources/ child.asp.

Yamazaki, A. (2002). Why change names?: On the translation of children's books. Children's Literature in Education, 33(1), 53-62. 


\section{Appendix A.}

\section{United Nations' Declaration of the Rights of the Child Plain Language Version (1959)}

1. All children have the right to what follows, no matter what their race, colour sex, language, religion, political or other opinion, or where they were born or who they were born to.

2. You have the special right to grow up and to develop physically and spiritually in a healthy and normal way, free and with dignity.

3. You have a right to a name and to be a member of a country.

4. You have a right to special care and protection and to good food, housing and medical services.

5. You have the right to special care if handicapped in any way.

6. You have the right to love and understanding, preferably from parents and family, but from the government where these cannot help.

7. You have the right to go to school for free, to play, and to have an equal chance to develop yourself and to learn to be responsible and useful. Your parents have special responsibilities for your education and guidance.

8. You have the right always to be among the first to get help.

9. You have the right to be protected against cruel acts or exploitation, e.g. you shall not be obliged to do work which hinders your development both physically and mentally. You should not work before a minimum age and never when that would hinder your health, and your moral and physical development.

10. You should be taught peace, understanding, tolerance and friendship among all people. 


\section{Biographical Notes}

Kasey Garrison is a lecturer in Teacher Librarianship in the School of Information Studies at Charles Sturt University in Wagga Wagga, New South Wales, Australia. Kasey earned a Ph.D. in Education with a focus on Curriculum and Instruction from Old Dominion University in Norfolk, Virginia, USA, in August 2012. With a Masters in Education and a Bachelors of Arts in Spanish, Kasey has experience at the preschool through secondary levels in the library and also teaching Spanish and students with special needs. Her research interests are focused on diversity within children's and young adult literature and reader responses to such titles.

Danielle Forest is an Assistant Professor of Elementary Education and Literacy at the University of Southern Mississippi in Hattiesburg, MS, USA, where she teaches courses in language arts and reading methods. She received her Ph.D. in Curriculum \& Instruction from Old Dominion University in May 2014. She has also earned a master's degree in Curriculum \& Instruction from the University of Massachusetts-Lowell and was a grade four teacher prior to her doctoral studies.

Sue Kimmel earned her Ph.D. in Curriculum and Instruction from the University of North Carolina at Greensboro in 2010. She is currently an Assistant Professor at Old Dominion University in Norfolk. Previously a selector for The Elementary School Library Collection, she has extensive experience reviewing children's literature and has served on the ALSC Caldecott, Newbery, and Notable Books for Children committees. Her research interests include multiple literacies and the socio-cultural impacts of children's literature. 
